\title{
Les monuments en Egypte en relation avec Saint Athanase
}

\author{
Mary Magdy Anwar \\ Professeur Assistant à la Faculté de Tourisme et d'Hôtellerie \\ Université d'Alexandrie, Section Guide.
}

\section{Résumé}

Depuis l'apparition du Christianisme en Egypte avec la prédication de Saint Marc, plusieurs patriarches se sont succédé à commencer par Saint Marc suivi par Saint Anianus, ensuite par dix-sept autres jusqu'à l'arrivée du vingtième pape Saint Athanase le Grand qui fut intronisé le 8 Bashans, en l'an 44 des martyrs- 328 ap. J.C., après le décès du pape Alexandre.

Ce pape est considéré comme l'un des patriarches les plus vénérés du siège de Saint Marc. Il guida l'église pendant 46 ans et fut exilé 5 fois loin de son siège.

Malgré les nombreuses persécutions qu'il subit, il demeure un des piliers de l'église copte orthodoxe.

C'est le premier pape qui ordonna le premier évêque de l'Ethiopie, dès que la situation religieuse de ce pays se fut stabilisée. Il fut également le premier à chercher le mélange de baume pour la préparation du Saint Chrême (huile de Myron) à Alexandrie. De même, il lutta acharnement contre l'hérésie d'Arius.
Ainsi ne pouvons-nous pas négliger les monuments qui lui sont associés. Cette recherche vise à éclaircir la biographie de ce Saint, les événements historiques qu'il vécut tout en mettant en évidence les principaux monuments qu'il édifia en Egypte telles l'église Saint Athanase à Alexandrie et la première église monumentale d'Abu Mina. Ceci s'ajoute aux lieux où il fut exilé et qui furent effectivement en rapport avec lui comme le Monastère El-Zawya situé au gouvernorat d'Assiout, la grotte du Monastère de Saint Mina le Suspendu à Assiout et bien d'autres monuments de la Haute Egypte. Ces monuments qui reflètent l'importance de cette personnalité remarquable, représentent une partie non indéniable de notre patrimoine copte.

Mots clés: Athanase, églises, monastères, exil, Alexandrie.

\section{Introduction}

Cent dix-huit papes coptes orthodoxes occupèrent le siège patriarchal, depuis la prédication de St. Marc à Alexandrie. Certains d'entre eux laissèrent une empreinte 
considérable sur l'histoire universelle tel que le pape Cyrille I, le pape Théophile I et le pape Athanase qui les avait précédés et dont la renommée traversa les siècles et les frontières. L'histoire relate d'habitude la biographie, les oeuvres théologiques sans se préoccuper de l'impact des papes sur des monuments qui perdurent jusqu'à nos jours. Plusieurs sources se sont concentrées sur les écrits du pape Athanase où il publia ses édits, sa défense de la foi, sa lutte contre les Ariens, la souffrance qu'il endura pendant 46 ans, la durée de sa papauté sans prêter attention aux divers églises et monastères qu'il édifia.

Cette recherche a donc pour objectif de mettre en relief les traces monumentales (les églises et les monastères ) associées au pape Athanase en Egypte tout en poursuivant les événements survenus dans sa vie, en mettant l'accent sur les chefs d'oeuvres artistiques coptes peints sur les murs des églises qui représentent ce pape et qui forment un héritage touristique copte indéniable.

\section{Les événements historiques en relation avec le pape Athanase:}

Il est difficile de poursuivre le parcours du 20ème pape d'Alexandrie "Saint Athanase" vu les avis divergents concernant sa vie personnelle et son enfance.

Il fut sacré après le décès du pape Alexandre I en l'an 326 ap. J.C. dont il était le disciple et le secrétaire et avec qui il avait participé au concile de Nicée en l'an 325 ap. J.C. où il avait défendu la vraie foi contre l'hérésie d'Arius ${ }^{1}$ (Livingstone, 1997, 119; Butcher, 1897, 141143; Wucher King, 1989, 174; كورور، 1974 1971) 191 1919 19). Il avait pendant ce temps une vingtaine d'année. Certains

1 Arius: prêtre d'Alexandrie, naquit en 250 en Libye et décéda en 336. Son hérésie consistait à approfondir le dogme chrétien de la Trinité.( Molinghen, 1968, 105) écrivains précisent qu'il naquit à Maria à Alexandrie en l'an 295-296 ap. J.C. (Kamil, 2002, 171), qu'il était issu d'une famille païenne, qu'il fréquenta les écoles d'Alexandrie (le Museion) et qu'il maîtrisa les langues

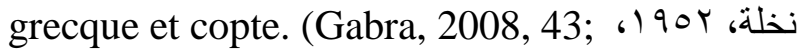

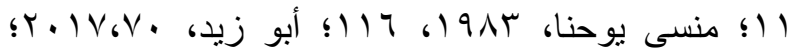

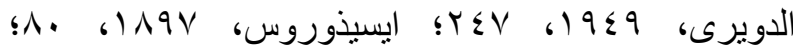

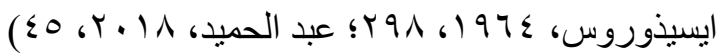

D'autres pensent qu'il était issu d'une famille chrétienne noble. (Cheneau, 1923, 533; لورور، $1 \leq$ (197r) Le père Matta El Meskin affirme que, d'après le manuscrit numéro 199, trouvé au monastère de St. Macaire, St.Athanase était né dans une famille chrétienne, il grandit à

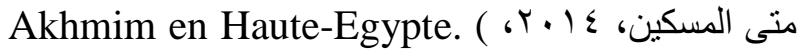
$r$ ) Certains autres pensent qu'il était grec vu son nom, mais seul le nom ne suffit pas pour

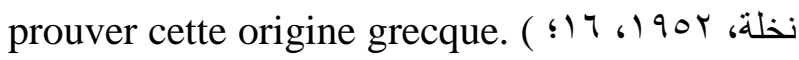

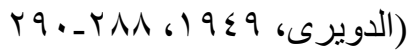

Comme ce fut l'habitude, sa famille se déplaça de la Haute-Egypte vers la capitale Alexandrie $^{2}$. Là, il grandit, devint étudiant à l'école théologique d'Alexandrie (Atiya, 1991,

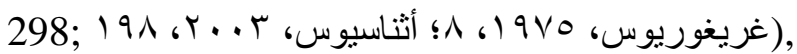
ce qui fut une des raisons pour laquelle il fut

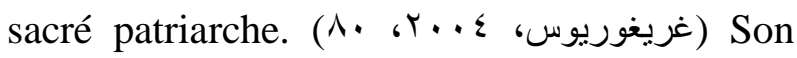
père décéda après 358 ap. J.C et fut enseveli à Alexandrie. Son tombeau,situé en dehors de la ville servit de refuge à Athanase. ( Socrates,

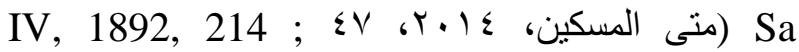
jeunesse nous est quasi-ignorée. Agé de 18 ans, il retourna peut-être en Haute-Egypte, où il fut le disciple de St.Antoine, le père des moines. (Cheneau, 1923, 534, Mackean, 1920,

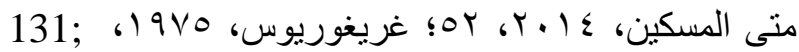
9)

${ }^{2}$ L'école théologique d'Alexandrie a été fondée par St.Marc pour confirmer la nouvelle religion. Il en était le directeur. Cette école enseignait toutes les sciences, à toutes les catégories sociales, hommes et femmes y avaient accès. Les bonnes relations étaient

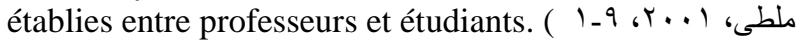
) 
Les 7 premières années de son épiscopat (328335 ap.J.C.) furent paisibles. Il alla en HauteEgypte en 330 ap. J.C. commença par El Miniya, Edfou et Aswan, longea le Nil pour arriver à Tabennesis où il rencontra St. Pachôme et ses disciples à la paroisse de Dendera. Il s'installa au monastère de Tabennesis, y fit une visite minutieuse des lieux, des cellules des moines, du refectoire, puis continua son voyage aux églises du Delta. (Davis, 2005, 58; Chauleur, 1960, 34-35;

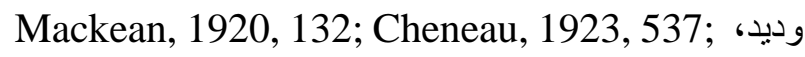
1)

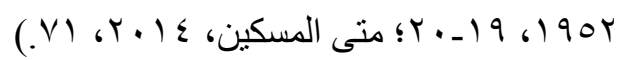

Le but de ses visites fut peut-être revoir les lieux de son enfance, ou encore consacrer cet endroit, ou répondre à sa nostalgie pour la vie monachique, ou enfin se rassurer que les moines là-bas n'étaient pas influencés par les idées d'Arius.

Pendant ce temps, en 330 ap. J.C il institua l'église de l'Ethiopie et ordonna l'évêque Furomnituis ${ }^{3}$.

Ce fut le premier pape à cuisiner "le Saint Myron" (le Saint Chrême) après St. Marc

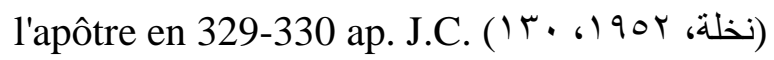

Suite à un ordre de l'empereur Constantin I, il se rendit à Jérusalem pour consacrer l'église de la Résurrection que la reine Hélène avait

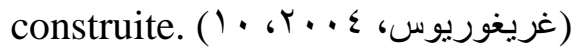

Période de trouble et d'exil:

La vie du pape Athanase se résume entre exil et réhabilitation.Il fut exilé 5 fois à cause des problèmes qu'il affronta avec les Ariens et les Méléciens. Ibn El Mokaffa souligna que ce pape passa 22 ans en exil et 25 ans en paix.(

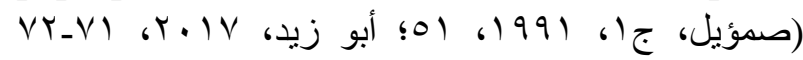

${ }^{3}$ Furomnituis était chrétien, d'origine syrienne. Ils furent lui et son frère Edisius prisonniers en Ethiopie. Là Furomnituis devint conseiller du roi "Nazana" et l'impressionna. De même il transféra les dogmes et les rites de l'église d'Alexandrie en Ethiopie. ( Tedeschi,

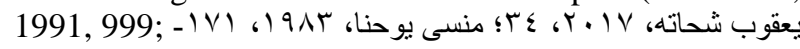
IVT
Mais El Maqrizi rapporta que le pape Athanase fut exilé 3 fois.(المقريزى، r. ( 1- Le premier exil à Trèves, située entre la France et l'Allemagne, dura 2 ans et 3 mois, de février 336 juqu'en mai 338 ap. J.C., sous le règne de l'empereur Constantin le Grand. Pendant cette période, il rédigea la vie de St. Antoine. Cette oeuvre eut une grande influence sur la vie ascétique chrétienne en Occident. (Livingstone, 1997, 119;

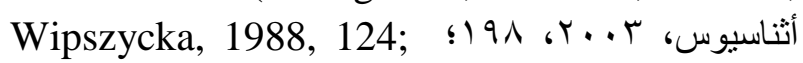

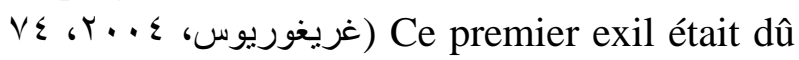
aux intrigues des Ariens qui avaient conspirés avec Eusèbe le Cesareum contre Athanase. Eusèbe avait convaincu l'empereur de pardonner à Arius qui était exilé et de le faire retourner à Alexandrie. Le pape Athanase brava l'ordre de l'empereur et interdit à Arius de prier à Alexandrie. Cet acte provoqua la fureur de l'empereur Constantin I. Par conséquent les Ariens tinrent le concile de Tyr pour accuser Athanase. Le pape était obligé de se rendre à Constantinople pour se défendre devant l'empereur. Ce dernier convoqua les Ariens pour qu'ils comparaissent devant lui et qu'il reconnaisse lui-même la vérité. Alors les Ariens le dénoncèrent, mentirent et prétendirent qu'Athanase voulait empêcher le transport de blé de l'Egypte à Constantinople, ce complot entraina le première exil du pape. ( Kamil, 2002, 172-173; Cheneau, 1923, 538544; Davis, 2005, 56; Livingstone, 1997, 119; Chauleur, 1960; 35-36; Wipszycka, 1988, 127 128; Butcher, 1897, 155-158; Socrates, I,

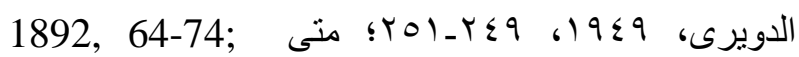

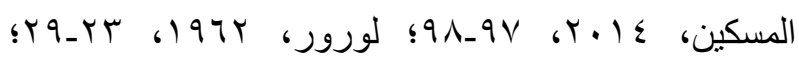

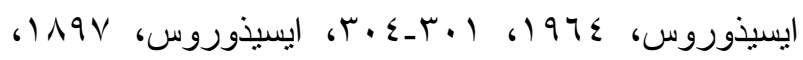

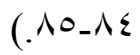

Une mort terrible mit fin à la vie d'Arius ${ }^{4}$. St. Antoine réclama à l'empereur le retour

4 Ses partisans préparaient son intronisation. Comme il tardait à les rejoindre, ils le cherchèrent, le trouvèrent jeté par terre, ses entrailles sorties de son ventre. (Cheneau, 1923, 545; Roncaglia, 1991,233) 
d'Athanase. Or, ce ne fut que sur son lit de mort que l'empereur autorisa le retour d'Athanase à son siège. (Cheneau, 1923, 544-

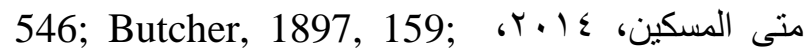

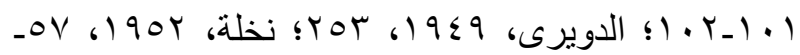

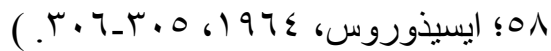

2- Les fils de l'empereur Constantin le Grand firent retourner le pape Athanase à son épiscopat. Les accusations des Ariens se succédèrent à l'aide de l'empereur de l'Orient Constantius. Athanase fut contraint de partir pour Rome pour exposer son problème devant les empereurs Constantin II et Constance. Ceux-ci l'aidèrent à reprendre ses fonctions. (Cheneau, 1923, 547-550; Livingstone, 1997, 119; Socrates, II, 1892, 81-84; منى المسكين، \& IV_lo ، A ce moment, les Ariens saisirent l'opportunité et nommèrent Grégoire de Cappadoce pape d'Alexandrie. Escorté de 5000 soldats, le pape Grégoire de Cappadoce assiégea l'église pour prendre position. (Hans,

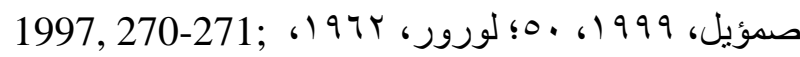

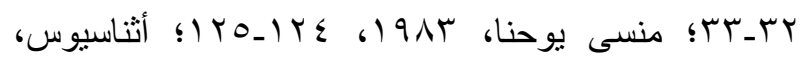
$191,4 \ldots r)$

Le pape Athanase s'enfuya de l'église de Théonas ${ }^{5}$ (Wipszycka, 1988, 128-129) et se retira à Nitria chez St. Amon ${ }^{6}$ puis regagna Rome comme 2ème exil. Il y eut des scènes de ravage, de chaos et l'église de Dionysios fut incendiée. (Socrates, II, 1892, 90; Butcher,

5 La Theonas: seconde église fondée à Alexandrie après Saint Marc La Boucoles, au nord ouest de la ville. Le pape Theonas (282-300) la bâtit après les années de persécutions des Romains. Elle devint la Cathédrale, mais perdit son importance au 6ème siècle. Plus tard, une mosquée " mosquée aux mille colonnes" fut fondée à sa place. ( Magdy, 2014, 208-209)

6 St. Amon: le vrai fondateur du groupe de moines à Nitria et Kellia, il naquit dans une riche famille chrétienne en 257. On l'obligea à se marier mais lui et sa femme vécurent chastes pour 18 ans. Puis il se rendit au désert de Nitria où un bon nombre de moines se joignèrent à lui. Sa relation fut étroite avec pape Athanase. Il installa la vie monastique à Kellia .

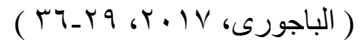

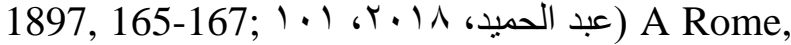
le pape Athanase écrivit pour la deuxième fois la vie de St. Antoine et de St. Paul. Après 7 ans d'exil de 339 à 346 ap. J.C. le concile Sardique $^{7}$ reconnut l'innocence du pape

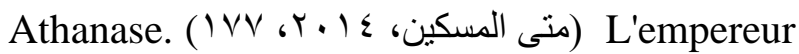
d'Orient Constance obligea son frère Constantius à accepter le retour du pape à son siège.( Cheneau, 1923, 551-553; Socrates, II,

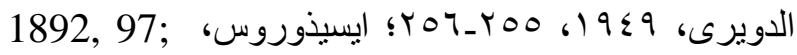
r.人 ، 197£)

Le pape ne se pressa pas d'arriver à son épiscopat. Il se rendit à Antioche, rencontra Constance, ensuite se dirigea à Jérusalem pour aboutir enfin à Alexandrie. (Cheneau, 1923,

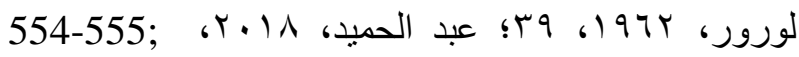
( $107 \mathrm{Il}$ avait atteint 48 ans, vécut alors 10 ans de calme du mois d'octobre 346 jusqu'à février 356 ap. J.C.(Chauleur, 1960, 37; وديد، I.r.r. $0 \leqslant \varepsilon$ ) Les moines Pachomiens l'honorèrent à Alexandrie. ( V0، $190 \mathrm{r}$ Y نظلة) Il choisit quelques uns et les consacra évêques; des moines qui lui avaient porté secours pour faire face à la

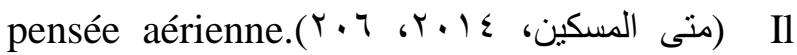
s'intéressa à l'école théologique d'Alexandrie et lui nomma comme directeur Didymus l'aveugle. ${ }^{8}$ (Butcher, 1897, 169; ، ،خلة ، 190 190 vo)

Pendant ces années de repos et avec l'augmentation du nombre de fidèles, le pape fonda d'autres églises à Alexandrie comme l'église de Cesareum. En Outre, il fut également le premier pape à s'intéresser aux reliques des saints. Il déposa ceux de Jérémie le prophète à l'église de l'ange au Vieux Caire et fit venir les reliques de St. Barthélémy le disciple et de St. Simon le Cananéen. (منى

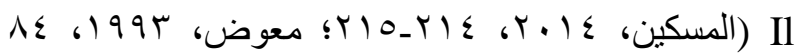

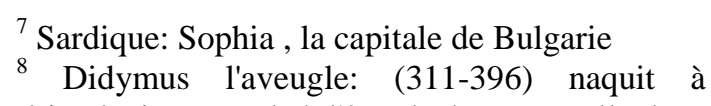
Alexandrie, devint aveugle à l'âge de 4 ans, excella dans les différentes études et sciences théologiques d'Alexandrie. Il s'éteignit à l'âge de 85 ans. ( ، نلة، 190 19 $7 \leq$ ) 
envoya une expédition de missionnaires en Inde qui avaient pour chef Afrondit qui devint par la suite évêque en Inde . (Jean de Nikiou, n.d., 309)

Mais, la mort de l'empereur Constance en l'an 350 déclencha, de nouveau, des conflits. (منى

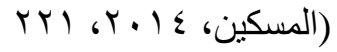

3- En l'an 355, une nouvelle assemblée se tint à Milan, par l'empereur Constantius, pour criminaliser Athanase (Davis, 2005, 58;

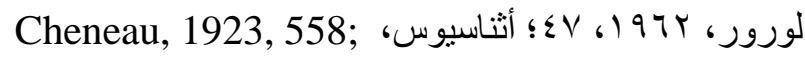
$1996 r . . r)$ pour avoir transgressé le commandement en officiant à l'église du Cesareum en 354, sans l'autorisation de l'empereur surtout que ce dernier avait eu l'intention de la bâtir pour les Ariens. (Butcher,

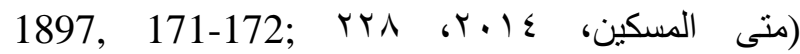
L'empereur envoya un de ses chefs armés pour enlever le pape Athanase mais cette tentative échoua en 355. En l'an 356 ap. J.C., le même empereur envoya des forces composées de 5000 soldats pour tuer le pape qui était cette fois-ci en train de prier les vêpres à la Théonas. Les fidèles aidèrent le pape à s'évader. (Butcher, 1897, 172-173; Kamil, 2002, 176; Chauleur, 1960, 38; Cheneau, 1923, 561; Socrates, II, 1892, 119-120; لورور،

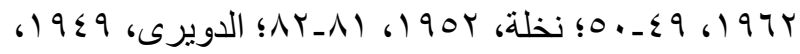

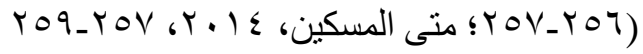

Le pape avait à choisir son exil, il préfèra, en fait se réfugier en Egypte parmi ses fidèles et ses moines entre les monastères de Wadi el Natroun et ceux de la Haute-Egypte. Ce fut une période prospère où il écrivit la moitié de ses livres et s'occupa d'un grand nombre de monastères. Anba Yousab, évêque de Fuah prouva par ses écrits que le pape Athanase résidait chez un teinturier à Akhmim (أبو زيد، $V \leqslant$ ، $Y \cdot \mid V)$ Ainsi, ce 3ème exil dura-t-il 6 ans du 8 février 356 au 21 février 362, jour de son retour à Alexandrie (Cheneau, 1923, 562-563;

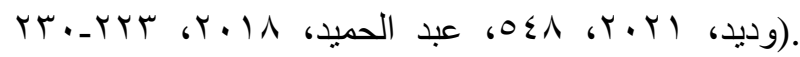
Durant ce temps, il se rendait clandestiment maintes fois à Alexandrie sans être reconnu et s'abritait dans une ancienne citerne (Sennoune,

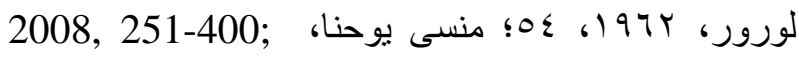
$141,19 \wedge r)$

Constantius décéda en l'an 361 quand

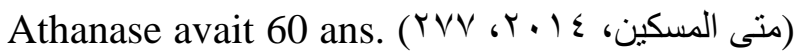
Julien devint roi et pratiqua le culte des idoles et ne s'intéressa point aux affaires religieuses. Il libéra les évêques exilés, entre autre Athanase (Cheneau, 1923, 563; Socrates, III,

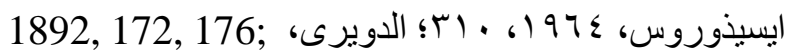
roV ، 19 १) qui connut uniquement 8 mois calmes.

4- Après son retour du 3ème exil, il eut pour projet d'unifier l'église. L'empereur Julien avait donné pour ordre de construire un temple païen à la place du temple de Jérusalem, (ce qui n'eut jamais lieu). Il fit incendier les cimetières des chrétiens en commençant par les tombeaux des prophètes Elysée et Jean Baptiste. Heureusement, les reliques de ces Saints demeurèrent intacts et furent par la suite transférées à Alexandrie chez le pape Athanase. (Jean de Nikiou, n.d., 314-315; نخلة،

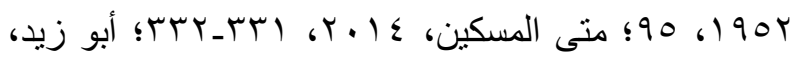

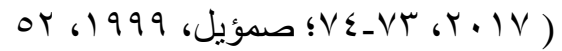

Huit mois après, Julien expulsa le pape Athanase parce qu'il ne lui avait pas donné l'ordre de reprendre ses fonctions à l'épiscopat et le pape avait baptisé bon nombre de personnes et avait tenu un concile à Alexandrie. (Chauleur, 1960, 40; Galtier,

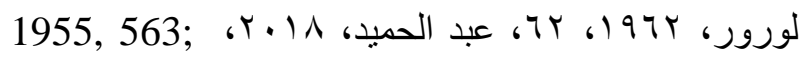
Le pape prit une felouque pour se sauver en Haute-Egypte chez les moines pachomiens (Cheneau, 1923, 570; (منسى يوحنا، rي Il fut poursuivi par une barque dont les poursuivants ne le

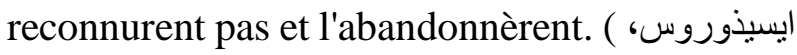

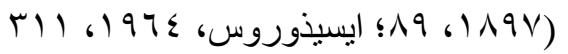

Là, 2 versions se présentent, l'une raconta qu'il retourna à Alexandrie pour s'y réfugier jusqu'à 
la mort de Julien en 363 ap. J.C. (Cheneau, 1923, 570-571; Socrates, III, 1892, 190) L'autre rapporta qu'il regagna Memphis (El Guiza) et séjourna au monastère de Tamuh ( Abu Sefein aujourd'hui ), (Atiya, 1991, 300;

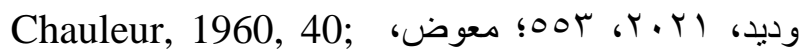

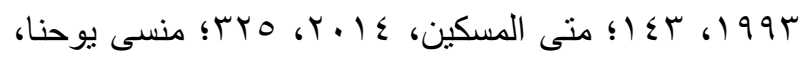
$1 \%$ เ $19 \wedge r$ ) ensuite se dirigea vers la HauteEgypte à Hermopolis (Malawi) puis à Antinopolis (Ansana) où il visita les monastères Kenobian, passa voir les églises, les réfectoires, les auspices et les hôpitaux; (

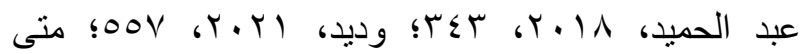
puis à Akhmim où il s'installa au monastère "Bafou". (Butcher,

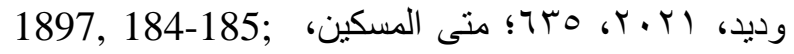

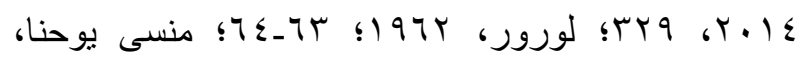

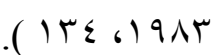

La première version paraît peu plausible parce que le pape était connu à Alexandrie, il aurait pu être facilement arrêté par l'armée mais en Haute-Egypte, il était plus en sécurité.

La mort de Julien en 363 mit fin au 4ème exil qui avait duré 15 mois. Comme l'empereur Jovian proclama le Christianisme religion officielle de l'état, le pape Athanase retourna à son siège apostolique. Il voyagea à Antioche pour remercier Jovian le 6 septembre 363 ap.J.C. ( Socrates, 1892, III, 208; Cheneau, 1923, 572-574; Jean de Nikiou, n.d., 322-323; Atiya, 1991, 300; Butcher, 1897, 187; Wipszycka, 1988, 131).

5- Jovian décéda le 17 février 364 après 8 mois de règne. Valentin devint gouverneur: 30 jours après, son frère Valens qui était arien devint son associé et gouverneur de l'Orient. (Socrates, 1892, IV, 211-213; Jean de Nikiou,

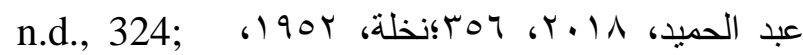

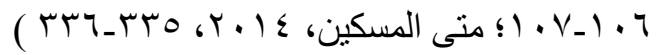

Par suite, en mai 365, un décret de l'empereur Valens ordonna à tous les évêques à retourner à leurs exils. Pour la 5ème fois, Athanase se retira de l'église Dionysios pour 4 mois pour se cacher dans le tombeau de son père (Butcher, 1897, 189; Chauleur, 1960, 40; Cheneau, 1923, 575-576; Socrates, IV, 1892, 228; Atiya,

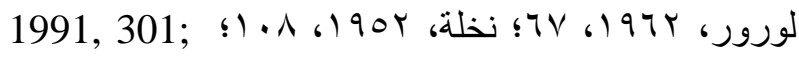

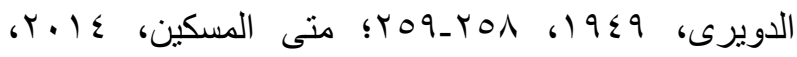

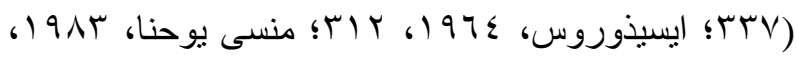
et dans les citernes, en dehors de la ville à demi-mille hors d'Alexandrie.(Sennoune, 2008, 72-87-197-209-334-402; Lubenau,1972, 216; Villamont, 1971, 240; Gonzales, 1977, 334; Palerne, 1971, 14)

Après la révolution des Alexandrins, le 1er février 366, il rentra de son exil, à l'âge de 70 ans. Cette période de paix dura jusqu'en 373.

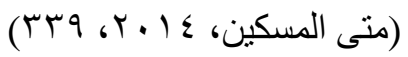

En septembre 368, après avoir passé 40 ans sur son siège épiscopal. Athanase fonda une église dans le quartier de Bennidion, la consacra le 7 août 370, elle fut nommée " l'église St. Athanase". La même année, il restaura l'église du Cesareum après qu'elle avait été incendiée en 366 ap.J.C. (Atiya, 1991, 301; Davis, 2005,

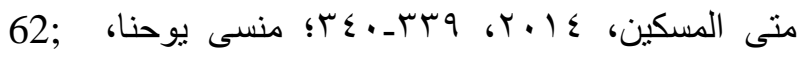
(r4، (19人r)

Enfin le pape Athanase mourut après 46 ans d'épiscopat en l'an 373. (Butcher, 1897, 190;

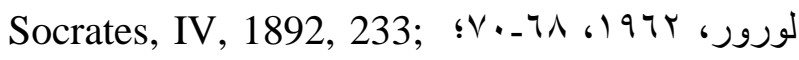

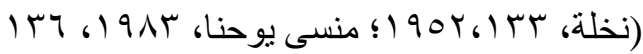

\section{Les monuments en relation avec le pape}

\section{Athanase:}

Avant d'aborder les monuments il faudrait commencer par les reliques de St. Athanase. Théodose Le Grand transféra le corps du pape d'Alexandrie à Constantinople qui était la capitale de l'état byzantin. Au 15ème siècle, la dépouille voyagea à Venise dans l'église Ste

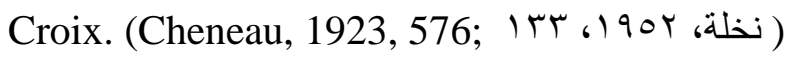
L'église Copte Orthodoxe fit de son mieux pour récupérer une partie des reliques du saint. Les négociations entre le pape Cyrille VI et l'église de Rome débutèrent en 1969. Mais ce n'est que le dimanche 6 mai 1973 que le pape 
Shenouda III put recevoir du pape Paul VI du Vatican ,un os de St. Athanase,déposé dans une coupe, en or pur fabriquée exprès pour

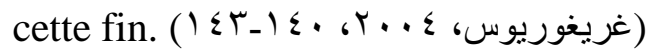

Ces reliques reposent actuellement dans la tombe située à l'ouest de deux églises celle de la Ste Vierge et Anba Riwyas et celle de la Ste vierge et Anba Bishoy, située au-dessous de la Cathédrale St. Marc à Abbasyia, appelée " la tombe de St. Athanase". (Meinardus, 2000,

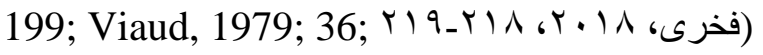

C'est une chapelle abritant un autel avec une niche décorée par l'icône de St. Athanase et dont le plafond représente le Christ entouré des 4 animaux de l'Apocalypse. ( جودت جبرا

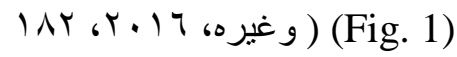

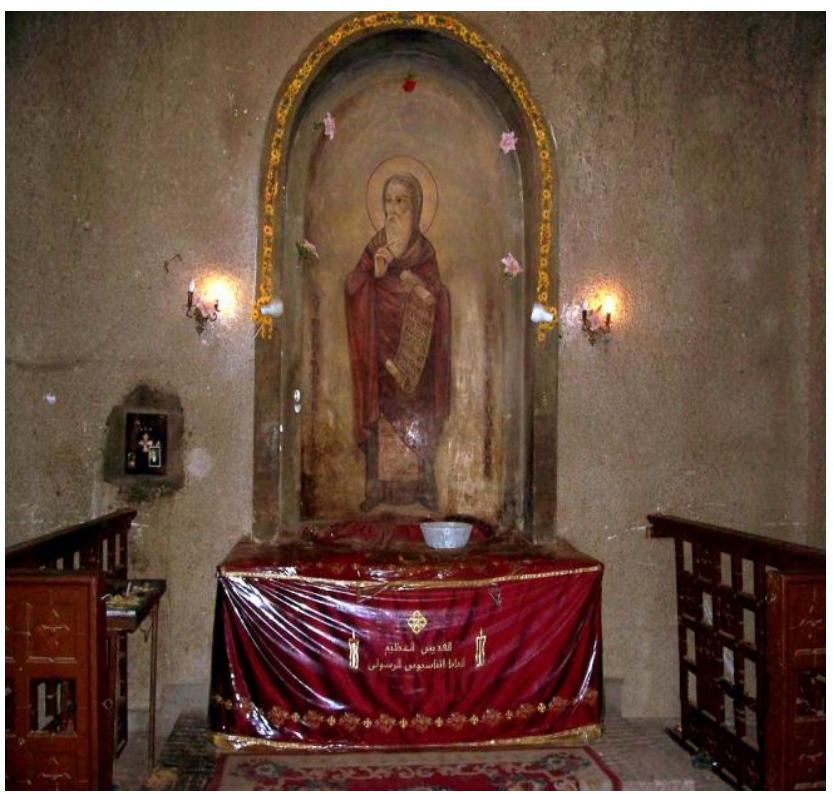

Fig. 1: La Chapelle de St. Athanase. Elle comporte un autel où reposent les reliques du Pape Athanase. de (https://www.wataninet.com/2020/05) (accès en 17-22021)

\section{Les églises en rapport avec St. Athanase à}

\section{Alexandrie:}

1- Le pape s'intéressa à l'église de Dionysios où il officiait. Elle fut incendiée et démolie comme on l'avait déjà cité. Pendant la période de paix qui succéda le 2ème exil, le pape édifia et rénova plusieurs églises parmi lesquelles celle-ci où il sièga jusqu'en l'an 370 ap.J.C., l'année où il bâtit l'église du Bennidion. (Gascou, 1998, 31; Sharaf el-Deen, 2008, 11-

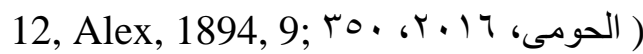

Cette église disparut avec le temps. Sur son emplacement, en 1856 les Grecs bâtirent une église "L'Evangelimos" située à la place AlManshia. (Magdy, 2014, 216)

2- Pendant la période de paix entre le 2ème et 3ème exil, il fonda l'église du "Cesareum" (350-355ap. J.C.) à laquelle nous avons fait allusion. (Martin, 1989, 1136-1137). Cette église se transforma en temple ${ }^{9}$ païen durant le règne de Julien, pendant l'absence $\mathrm{du}$ patriarche. Elle fut brûlée par les païens et les ariens en 366. En 368, le pape Athanase la restaura et la dédia à l'Archange Michel. (Meinardus, 1965, 114-115; Martin, 1984, 217-218; Forster, 2012, 133; Magdy, 2014, 213)

Ibn Kabr, au 14ème siècle, précisa l'importance particulière de cette église, en expliquant que les papes devaient se rendre en 3 églises à Alexandrie après leur intronisation et parmi lesquelles figurait cette église. (ابن r

3- En 370, le pape Athanase fonda une église complète qui fut plus tard baptisée l'église"d'Athanase". (Morison, 1976, 14; Vaujany, 1885, 107-108).

En 1636, Neitzschitz fit allusion aux églises d'Alexandrie dont l'une est celle de St. Athanase ( Neitzschitz, 1974, 197); et en1668, Ferdinaud von Troilo visita l'église de St. Jean l'Evangéliste croyant que c'était là que "St. Athanase était enseveli... et indiqua que cette

9 Temple du Cesareum: «Kaiserion » fut construit par Cléopâtre VII qui voulait honorer son mari Marc Antonio et son fils Kaisareion. Elle le fonda au bord du port oriental, actuellement Gare de Ramleh dans l'endroit de l'hôtel Métropole. Puis il a été complété par Auguste le nommant «Sebasteon».

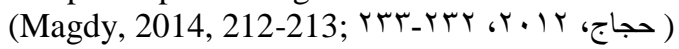


même église s'était transformée en mosquée turque..." (Sennoune, 2008, 476).

Mais comme il fut déjà signalé, le pape n'aurait pas pu être enseveli là puisque la dépouille était déjà transférée en Rome durant ce temps.

D'autres voyageurs visitèrent l'emplacement de l'église St. Athanase qui était devenue une mosquée. ( Brown, 1974, 22; Sennoune, 2008,505-550-599-638-657-661-719; Volkoff, 1972, 95-96)

Même St. Jenny, un des savants de l'expédition française décrivit la mosquée en la surnommant " Mosquée de St. Athanase" ( Magdy, 2014, 212; أحد علماء الحملة الفرنسية، $r V \varepsilon-r \leqslant r(r, . r)$

D'autres découvrirent un grand sarcophage, qui figure actuellement au musée britanique, dans le sanctuaire qui demeura 12 siécles dans la mosquée.( Wilkinson, 1847, 101; Vaujany, 1885, 108-109). Bref, l'église de St. Athanase devint la mosquée El-Attarine.

\section{$\underline{\text { L'église de la Crypte de St. Mina (la tombe) }}$}

\section{à Mariout- église de St. Athanase:}

L'ancienne cité d'Abou Mina à Mariout située à 45 mille $\mathrm{Km}$ d'Alexandrie, considérée une des régions du patrimoine mondial d'après l'UNESCO, témoigne des vestiges d'une église attribuée et bâtie par le pape Athanase. Comme le dit Abu El-Makarim, "c'est le pape Athanase qui repeupla le désert." ( صمؤيل، $1 \leqslant 0,19 \wedge \varepsilon$ )

Perkins souligna que, d'après le manuscrit copte numéro 590, découvert dans la région El-Hamuly au Fayoum, qui date de 893, conservé à la bibliothèque "Pierpont Morgan", écrit par Anba Youhanna l'archevêque d'Alexandrie; (Perkins, 1949, 30) il s'avère que quand les pélerins se multiplièrent dans cet endroit, ils demandèrent à Athanase d'élargir l'église. Le pape rétablit cette église en 363 ap.J.C. avec l'aide de l'empereur Jovian qui finança les constructions. Elle était réalisée en marbre doré. Les travaux furent achevés sous le règne des empereurs Valentinian et Valens qui envoyèrent le préfet d'Alexandrie Tatian. Ce dernier attesta de la sainteté de ce lieu qui contenait la tombe de St.Mina. Les évêques consacrèrent l'église en 375 ap.J.C.(Perkins,

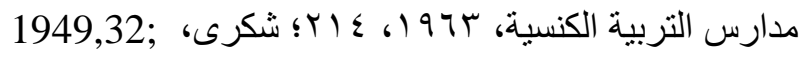
Ar, r. II)

Or, Grossmann pense que cette église n'a rien à voir avec St. Athanase. D'après lui elle fut fondée après le décès de ce pape. (Grossmann, 1991, 14; Yr_r. ، جروسمان، (9197) mais ces paroles ne furent pas prises en considération.

Après son retour du 5ème exil, le pape Athanase ériga cette église en forme d'oratoire de style tetrapylône sur l'emplacement du tombeau de St. Mina et veilla à restaurer le tombeau. Ce fut la première étape de construction. (Meinardus, 1965, 141; Meinardus, 2002, 70; 17 ، الثاذلى، 0. Mais Capuani affirma que cette église fut construite par l'empereur Constantin I comme oratoire, puis en 2ème étape reconstruite par St. Athanase, puis comme 3ème étape par St.Théophile. (Capuani, 2002, 49) Et Viaud l'attribua au pape Athanase qui l'avait consacrée le 15 Bauunah (22 juin). (Viaud, 1979,5)

Badway prétendait que c'était l'empereur Constantin I qui l'avait construite et que c'était Theodose I qui l'avait consacrée, et ne mentionna point le nom du pape Athanase. (Badway, 1957, 16)

Nous devrions éclaircir que le règne de Constantin I concordait avec l'ère du pape Athanase, c'était donc normal que cette église fût construite et consacrée par lui.

Les traits architecturaux de la Crypte et de l'église:

Pape Athanase transforma la catacombe en brique crue de St.Mina en crypte en pierre. (Capuani, 2002,52) 
Le tombeau changea totalement de forme à travers les siècles. Cependant une partie de la muraille de l'est exécutée par Athanase demeure jusqu'à nos jours. Ce tombeau se compose d'un arc vouté qui fut plus tard bloqué en pierre par pape Théophile quand il érigea l'entrée nord de la crypte. Cet arc s'ouvrait sur un passage, voûté tapissé de plâtre, qui remontait vers l'est sur l'axe de l'église et qui était probablement l'entrée de l'actuelle chambre funéraire reliée à l'église de St. Athanase. (Perkins, 1949,41; مدارس التربية

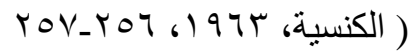

Quant à l'église qui donne directement au tombeau, il n'en reste que les bases, c'était une église sous forme de "T". (Fig. 2) A l'est de l'église, le sanctuaire se composait d'un autel au milieu, disparu maintenant, et vers son est, une abside figure flanquée de 2 absidales.(

$$
\text { r. (شكرى، (I) }
$$

Des 2 côtés du sanctuaire, on trouve les restes des 4 murailles formant 2 chambres de l'extérieur auparavant utilisées comme ailes latérales, et 2 chambres de l'intérieur collées au sanctuaire formant l'entrée vers la tombe. La nef se répartissait en 3 parties séparées par des colonnes en marbre avec des chapiteaux à décoration d'acanthe. Une citerne en forme d'un passage de $80 \mathrm{~m}$. de longeur, fournissant l'eau miraculeuse occupait la partie ouest. Elle amenait à un puits qui donnait accès à l'église. (Perkins, 1949,42-44; Badway, 1957, 18-20; YON_rOV ، مدارس التربية الكنسية، (Fig. 3)

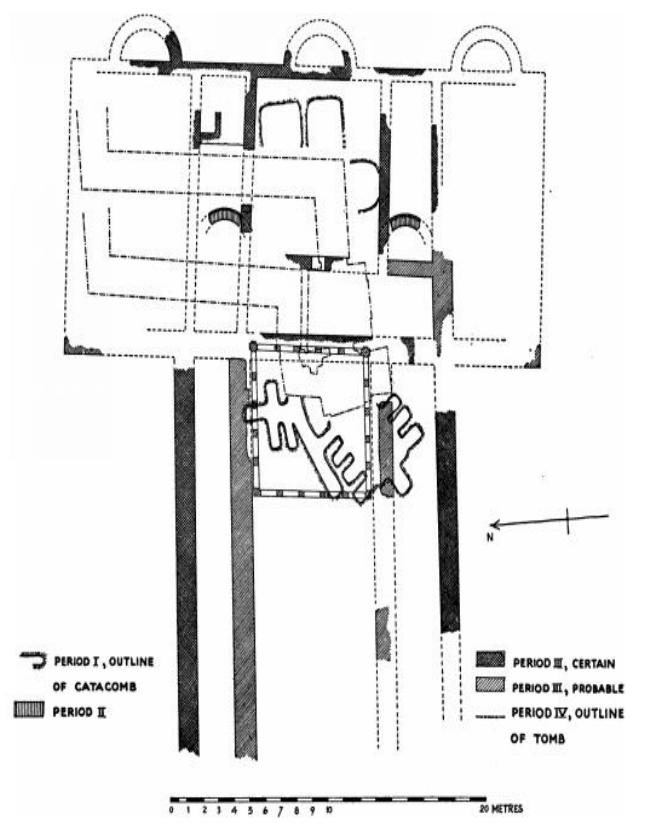

Fig. 2: Plan de l'église de St. Athanase. (Perkins,1949, 42).

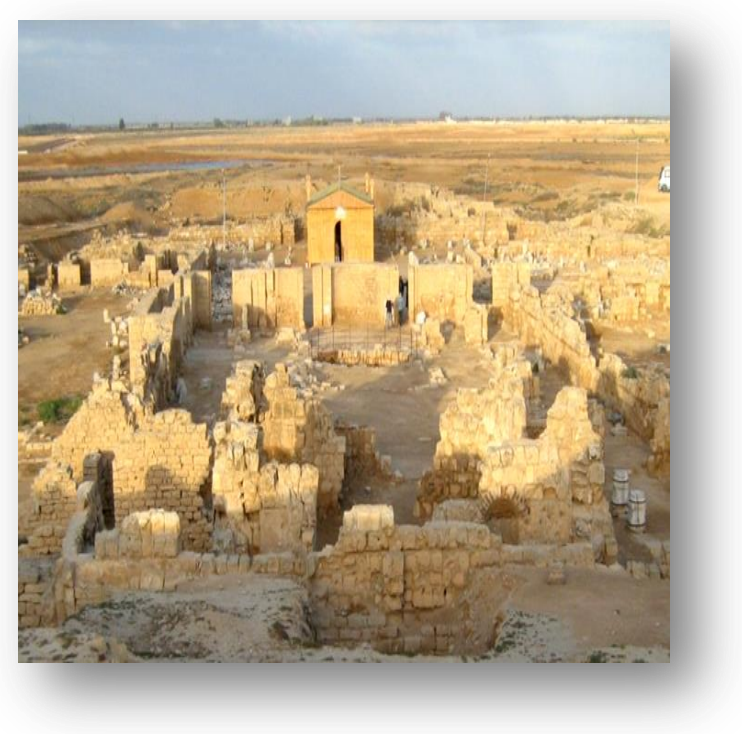

Fig. 3: Les ruines de l'église de St. Athanase entre la grande basilique du pape Théophile et le baptistère. () Copyright par l'auteur).

Cette église existe jusqu'à nos jours. Elle est située entre la grande basilique du pape Théophile et le baptistère qui remonte au pape Thimothé. 
Les Eglises et les monastères liés à St. Athanase en Haute-Egypte:

I- Le monastère Suspendu de St.Mina à Asyuit:

Ce monastère se situe au nord du village ElAbada, à l'extrémité sud du Gabal Abu-Fuda à Asyuit. (Martin, 2015, 105) Il fut cité par St. Athanase dans ses édits. (معوض، 109 199 199)

D'après la tradition, ce monastère remonte à l'ère de la reine Hélène. (Meinardus, 1965, 386) Cette reine, mère de Constantin le Grand était passionnée par l'édification des églises. Elle avait même demandé au pape Athanase de se rendre à Jérusalem pour la dédicace de l'église de la Résurrection. En fait, le pape Athanase bénéficia de cette période de bienveillance de la reine et se rendit également à Asyuit pour la consécration du monastère de St. Mina, son intercesseur.

Certaines personnes pensent que le pape Athanase s'était dirigé pendant le 4ème exil vers ce monastère pour se cacher dans la grotte monumentale, où il consacra l'autel à St. Mina.

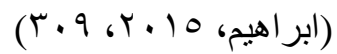

Ce monastère eut plusieurs appellations" le Suspendu" étant donné qu'il était suspendu et creusé de la montagne d'Abu-Fuda; (Fig. 4) (Meinardus, 1965, 385; Viaud, 1979, 50-51; r9، 199 199 monastère de la Grotte de Shiqilqil" à cause de ses trous creusés au flanc de la montagne, qui donne sur le Nil, ( المقريزى، (r) et aupres duquel se trouvait $\left.1 \cdot r r_{-} \mid \cdot r_{1}, r_{*} \cdot r\right)$ et auprès duquel se trouvait une tombe de crocodiles momifiés; (Martin, 2015, 105; Coquin\& Martin, 1991, 834; Doresse, 1970, 20) et enfin "Couvent de la poulie" parce que les moines utilisaient une corde pour y avoir accès. (Wilkinson, 1874, 309)

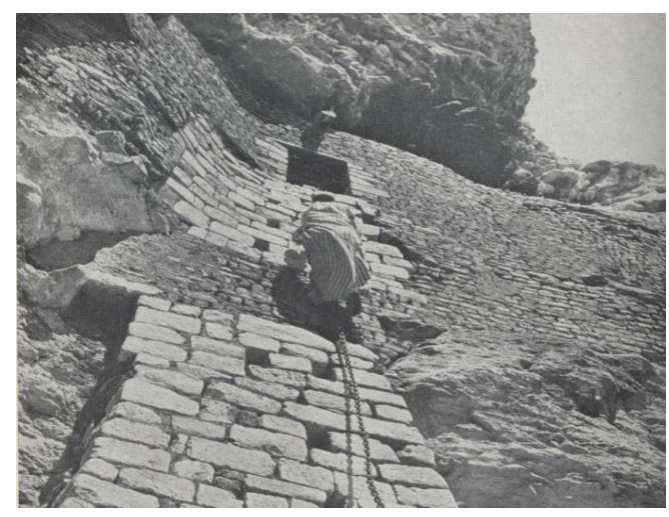

Fig. 4: "Le Suspendu". Il était suspendu et creusé dans la montagne d'Abu-Fuda. (Doresse, 1970, 22)

Les pélerins venaient chaque année le 18 bauwnah prendre la bénédiction de St. Mina. (Viaud, 1979, 51; Meinardus, 1965, 386)

Ce monastère qui fut restauré par le Haut Conseil des Antiquités en 1998 comporte 3

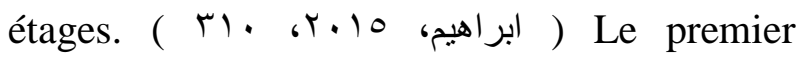
contient une salle en forme de cuisine qui donne sur le donjon, le second se compose de trois salles, dont l'une servait pour les donations et qui est devenue une cimetière pour les moines. L'église de St.Mina occupe le 3ème étage, elle abrite un autel. (Meinardus, 1965, 386) Cette église est creusée dans une profonde grotte qui servait comme refuge au pape Athanase. ( صمؤيل، د.ت، ع)

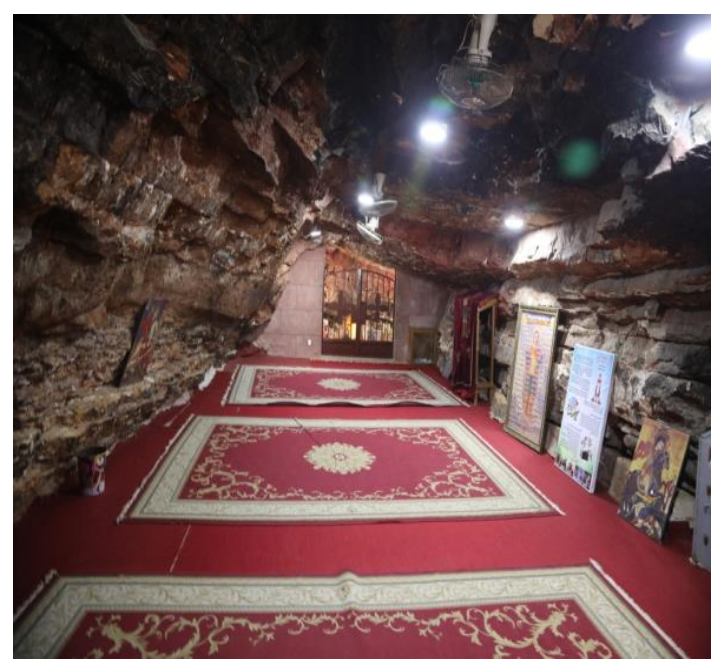

Fig. 5: La Grotte (le refuge de St. Athanase) (ㅇ Copyright par l'auteur). 


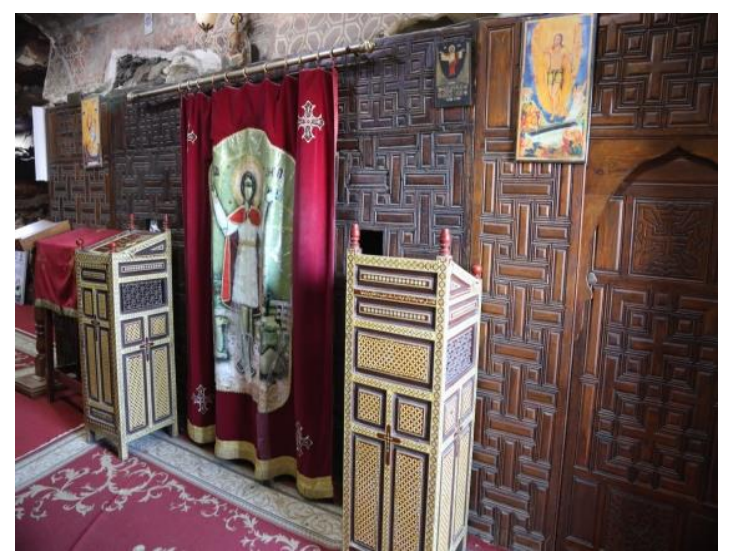

Fig. 6: L'ancienne église de St. Mina (ㄷ Copyright par l'auteur).

Ce monastère fut récemment renouvelé, un nouveau bâtiment de 4 étages y fut ajouté. (معوض، س I I I 199 109 renferme actuellement 4 églises, celle de la Grotte, (Fig.5) l'église de la Vierge Marie et l'Archange Michel qui était à l'origine un temple pharaonique, l'ancienne église de St. Mina (Fig. 6) et l'église de St. Athanase et St Arsène au 2ème étage du donjon bâti en brique crue. (هبان دير مارمينا، (Y)

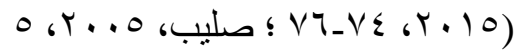

La vie monastique reprit le 2 juin 2001 pendant l'épiscopat du pape Shenouda III.

II- Le monastère de St.Athanase "AlZawya" à Asyuit:

En pénétrant dans le monastère, on trouve écrit" Monastère du pape Athanase AlZawya". Il s'agit de l'unique monastère monumental qui porte le nom de ce pape et qui

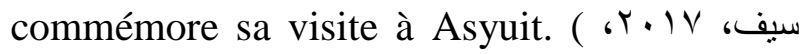
५१) (Fig.7)

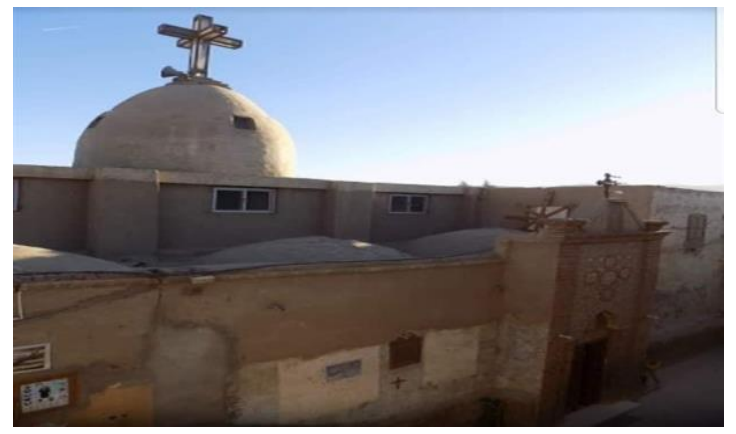

Fig. 7: L'entrée principale du" Monastère du Pape Athanase Al-Zawya". de (https://www.wataninet.com/2020/05) ( accès en 17-2-2021)
Il se situe dans un village copte connu sous le nom "couvent Al-Zawya" à $15 \mathrm{~km}$ sud-ouest d'Asyuit, à 5 km d'El-Rifa,à peu de distance d'Aboutig, (Meinardus, 1965, 397; Meinardus, 2000, 227; Capuani, 2002, 199; Martin, 2015, 128; Coquin \& Martin, 1991, 884; Doresse, 1970, 24) il fut séparé pendant la période Ottomane des villages d'El-Rifa, pour devenir Zawyat Asyuit. ( YV، 199 996 (رمزى)

D'après les chroniqueurs, ce monastère eut plusieurs appellations:

Il fut d'abord nommé "Dayr Al-Zawiya", les moines étant considérés comme des Apôtres, El-Maqrizi précisa qu'il s'appelait également "le couvent des Apôtres". Comme il était entouré de jardins, il connut de même le nom

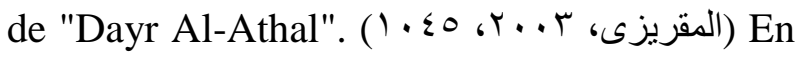
plus l'appelation "monastère des Scribes" lui fut attribuée parce que ses moines étaient renommés pour leurs écritures des livres saints. ( IAV، r • • ابر اهيم، 0 )

Vansleb cita:" de Siut au "monastère de St. Athanase".. qui était un des plus misérables des monastères." (Vansleb, 1677, 377-378). Clarke répéta le nom de "Dayr Al-Zawya" qui figure jusqu'à nos jours dans la liste des monastères d'Asyuit. (Clarke, 1912, 211)

En 1932, Marcus Simika et Al-Masouidi affirmèrent la présence de l'église de St. Athanase à l'intérieur du monastère Al-Zawya

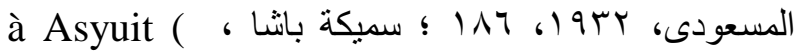

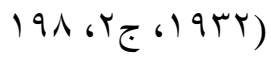

Effectivement, ce monastère porte le nom du pape Athanase; là où il veillait personnellement sur les moines de ce monastère de peur que ceux-ci ne soient influencés par l'hérésie des Ariens. (رياض، $79.71 .1991)$

En revanche, Doresse mentionna:" On ignore à qui cette basilique fut dédiée jadis, peut-être à la mémoire d'un moine d'Antinoë nommé 
Athanase (début du V siècle?)" (Doresse, $1970,24)$ Cet avis nous semble peu vraisemblable, cet Athanase était un simple moine inconnu et avait séjourné dans le district de Mallawi et dans un siècle tardif à celui du pape Athanase, qui nous intéresse, ce qui contredit les paroles des chroniqueurs.

Le monastère actuel diffère de l'ancien, il ressemble à une citadelle, forme même un vaste quadrilatère de 80 à 100m entouré d'une vaste enceinte, avec une entrée haute principale à l'ouest en pierre qui nous conduit à l'église de St. Athanase. (Coquin \& Martin, 1991, 884; Martin, 2015, 128; جبرا وآخرون، Yтฯ, r.17)

L'église actuelle fut reconstruite sur les ruines de l'ancienne église, avec l'entrée à l'est décorée avec des figures géométriques. Elle est en style byzantin, qui se compose de 13 dômes symboles de Jésus et des 12 disciples, dont la coupole principale supportée par 4 colonnes massives se dresse dans la nef centrale entourée des 2 ailes. A l'ouest de l'église, se trouve le narthex transversal voûté. Un iconostase en bois décoré de croix et de formes géométriques sépare le sanctuaire principale de la nef. ( ابر اهيم، 10

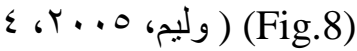

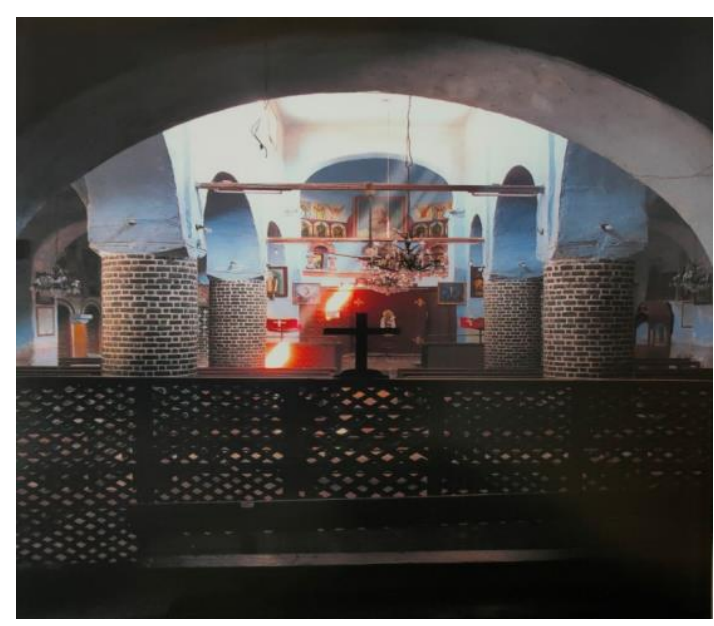

Fig. 8: L'église actuelle du" Monastère du Pape Athanase Al-Zawya".

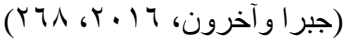

L'endroit le plus ancien de l'église est son sanctuaire dédié à St. Athanase qui date du 5ème- 6ème siècle (صمؤيل، د.ت، 97 (صمات) unique dans ses motifs avec ses niches pentagones réparties en 2 registres. Dans le registre inférieur, on voit 3 arcades en plein-centre décorées par de motifs géométriques et bandeaux floraux et 2 portes arquées donnant sur 2 chapelles plus basses. Au-dessus, le registre supérieur comporte 5 niches hautes à fronton brisé flanqué par des petites colonnes, 4 sont décorées par des coquilles et la centrale avec une colombe (?) ou un aigle. (Capuani, 2002, 199; Martin, 2015, 128; Coquin\& Martin, 1991, 884; ابراهيم، 0 (Fig.9)

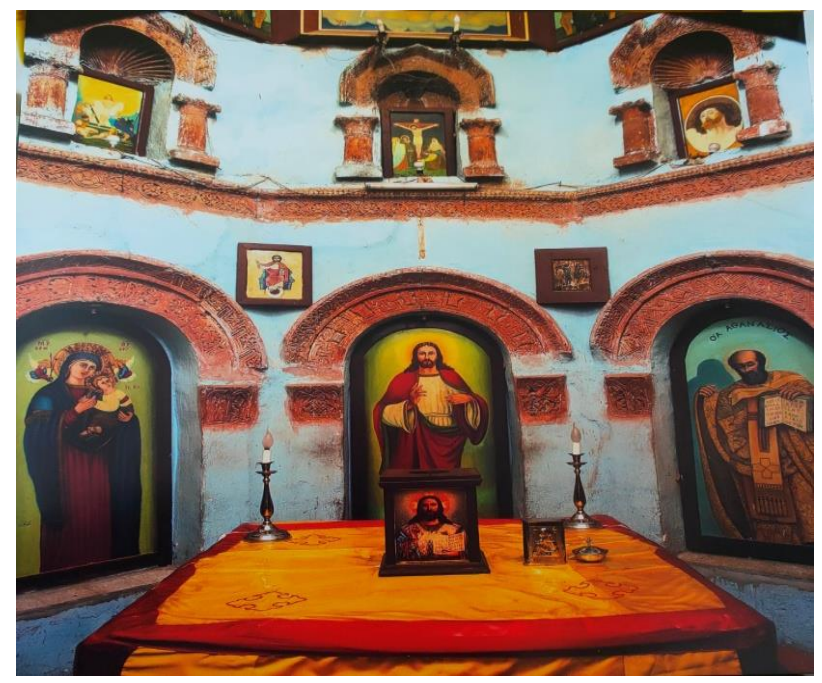

Fig. 9: L'endroit le plus ancien de l'église est son sanctuaire dédié à St. Athanase qui date du 5ème- 6ème siècle.

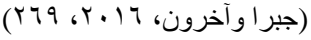

$\mathrm{Au}$ 18ème- 19ème siècle, une église fut consacrée au pape Athanase au village ElSolia Mattay, à l'ouest de Beni Mazar, dont la nef se compose de 9 dômes et les sanctuaires de 3 dômes. (صمؤيل، د.ت، 0 )

Les peintures murales en rapport avec St. Athanase:

Grâce à la réputation et l'importance du pape Athanase, plusieurs peintures murales furent récemment découvertes représentant ce pape. 
Le Monastère Rouge de Sohag comporte, dans l'église monumentale dans le premier rang du triconche au nord, la représentation de 3 patriarches: Athanase, Théophile et Cyrille I. Celle d'Athanase date du 6ème- 7ème ou 8ème siècle. (Bolmann, 2016,3; Farag, 2004, 46) On y observe le buste de ce pape avec une tête auréolée, des yeux perçants, un visage ovale, un long nez et barbu. Il est revêtu d'un sticharion blanc et un épitrichalion en-dessus. (Fig.10)

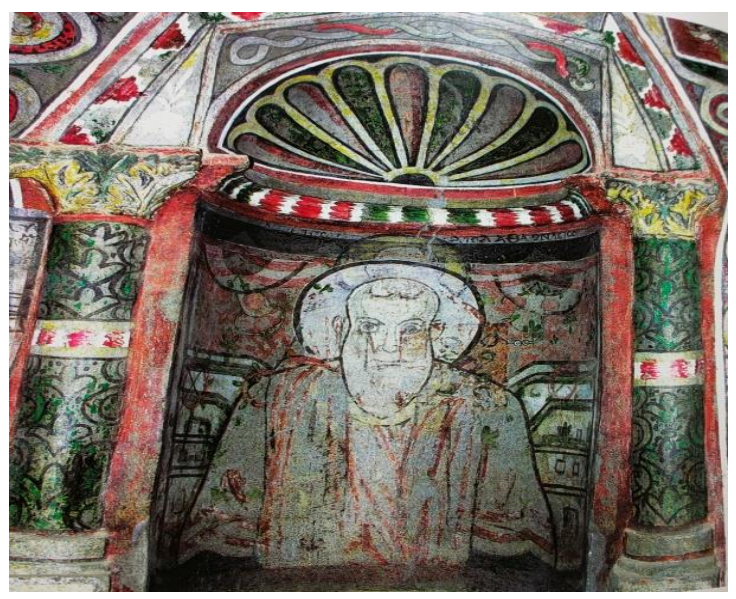

Fig. 10: La peinture murale de St. Athanase dans le Monastère Rouge de Sohag. (Bolman, 2016, 2)

A Tebtinius El-Fayoum, une autre peinture murale qui date de l'an 953, représente St. Athanase à côté de la niche du Christ. St. Athanase trône avec un aspect calme entre les 2 fondateurs du monachisme St. Antoine et St. Pachôme. (Davis, 2005, 55) ( Fig.11)

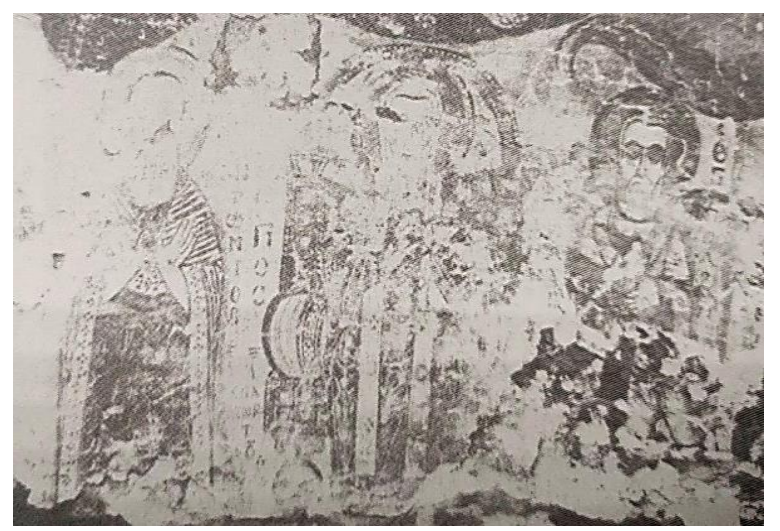

Fig. 11: La peinture murale de St. Athanase à Tebtinius El-Fayoum. (Davis, 2005, fig.4)
En plus,le Monastère de St. Antoine à la mer rouge, renferme dans la chapelle droite, au fond du sanctuaire, dans le registre inférieur de la niche une représentation symbolique de St. Athanase, à gauche du Christ. Elle éclaircit le rôle du pape Athanase "pilier de l'église". Il est ici associé à 2 grands pères exceptionnels de l'église (Syriaque et Copte) "St. Sévére et St. Dioscore" "miaphysite" et non "monophysite". (Sadek, 2003, 61)

St. Athanase est représenté comme un veillard barbu, trônant, portant un nimbe orange. Il est coiffé d'un capuche de moine noir. Il porte un skéma au-dessus d'un sticharion dont les manchettes sont décorées de carrés dessinés en rouge. Les extrémités de l'épitrichalion sont ternies. Un codex repose sur l'avant-bras gauche. (Moorsel, 1995, 75-77) (Fig.12)

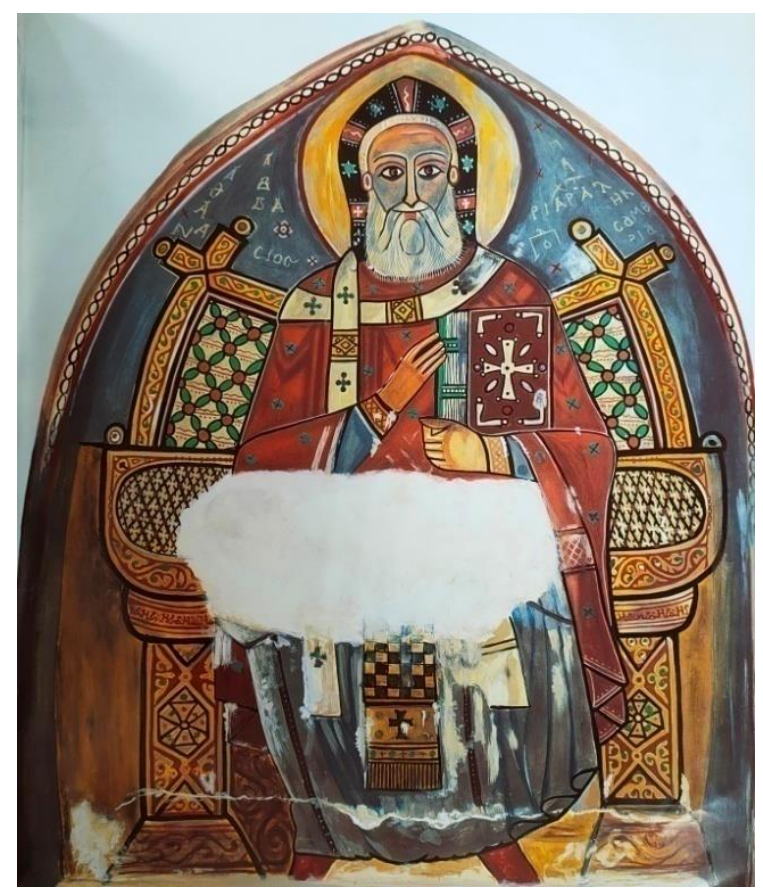

Fig. 12: La peinture murale de St. Athanase dans le monastère de St. Antoine à la mer rouge. (Moorsel, 1995, Vol.2, 28)

Après avoir signalé le côté historique du pape Athanase ainsi que les monuments qui lui sont attachés nous pourrions conclure par ce qui suit:

Les travaux de construction tels les forteresses, les maisons et les églises sont souvent 
attribuées aux rois ou aux empereurs des époques. Or, malgré toutes les épreuves que le pape Athanase endura durant sa vie, il était doté d'un pouvoir absolu. Quand le peuple désirait bâtir une église, il s'adressait directement à lui surtout que pendant cette ère byzantine, aucun empereur ne visita l'Egypte. En outre, comme une partie de l'épiscopat du pape Athanase concordait avec le règne de l'empereur Constantin le Grand et de sa mère la reine Hélène qui avait un engouement particulier pour la construction des églises, le pape Athanase en profita pour construire des églises surtout après des périodes de persécution.

Le pape Athanase fut également le premier pape à s'intéresser à la consécration du Myron et à la conservation des reliques des saints ce qui se justifie par sa construction de maintes églises pour conserver leurs reliques.

De même, le nom de ce pape fut associé à deux principales régions: D'une part la ville d'Alexandrie considérée comme siège patriarchal où il résida et rétablit plusieurs églises. D'aute part, la Haute-Egypte où il se rendait; à savoir Memphis, Minya, Asiyut et Akhmim, lieu de sa nativité.

Par ailleurs, ce pape prit soin de la vie monastique, il écrivit divers ouvrages grâce auxquels le monachisme se répandit dans tout l'Occident.

$\mathrm{Vu}$ l'importance de ce pape, son corps ne demeura pas à Alexandrie. Les byzantins s'en emparèrent pour le conserver chez eux, puis la dépouille partit à Rome.

Les peintures murales qui le représentent illustrent son importance. Il est peint auprès du Christ lui-même et avec de grands saints, soit avec de grands papes ou avec les fondateurs du monachisme.

Ne faudrait-il donc pas prêter plus d'attention aux monuments qui lui sont attachés et qui constituent de la sorte un patrimoine copte riche en trésors et en vestiges surtout qu'il est certain qu'il en reste encore beaucoup à découvrir?

\section{Bibliographie}

- Alex, Max de Zogheb (1894), L'église d'Alexandrie, communication faite à l'institut égyptien dans la séance du 5 janvier 1894, imprimerie Nationale, Le Caire.

- Atiya, A. (1991), "Athanasius I", in CopEnc I, macmillan publishing company, New York, pp.298-302. - Badway, A. (1957), Les Premières Eglises d'Egypte jusqu'au siècle de Saint Cyrille, Editions du scribe égyptien S.A.E., Le Caire.

- Bolman, E. (2016), The Red Monastery church (Beauty and Asceticism in Upper Egypt), Americain Research in Egypt, Yale University press, New Haven and London.

- Brown, E. (1974) Voyage en Egypte 1673-1674, Traduit par: Marie-Thérèse Brièant, 10ème vol., IFAO, Le Caire.

- Butcher, E.L. (1897), The story of the church of Egypt (Being an outline of the history of the Egyptians under their successive masters from the roman conquest until now), London.

- Capuani, M. (2002), Christian Egypt (Coptic Art and Monuments through Two Millenia), AUC Press, Cairo.

- Chauleur, S. (1960), Histoire des Coptes d'Egypte, Ed. Du vieux colombier, Paris.

- Cheneau, P. (1923), Les Saints d'Egypte, t.1, Couvent des RR.PP. Franciscains, Jerusalem.

- Clarke, S. (1912), Christian Antiquites in the Valley of the Nile, Oxford.

- Coquin, R.G. et Maurice Martin (1991), Dayr AlZāwiyah, CoptEnc 3, Macmillian publishing company, New York.

- Coquin, R.G. et Maurice Martin (1991), Dayr Mār Mina, CoptEnc 3, Macmillian publishing company, New York.

- Davis, S.J. (2005), The Early Coptic Papacy (The Egyptian church and its leadership in Late Antiquity), $2^{\text {nd }}$ printing, AUC press, Cairo.

- Doresse, J. (1970), "Monastères Coptes de MoyenneEgypte", Bulletin de la Société française d'Egyptologie, Vol.59, Paris, pp.7-29.

- Forster, E.M. (2004), Alexandria ( A History and a Guide and Pharos and Pharilion), edited by Miriam Alott, AUC press, Cairo.

- Gabra. G.(2008), Historical Dictionary of the Coptic Church, AUC Press, Cairo. 
- Galtier, P. (1955), " Saint Athanase et l'âme humaine du Christ", dans: Gregorianum, Vol.36, No.4, published by: Gregorian Biblical press, pp. 553-589.

- Gascou, J. (1998), "Les églises d'Alexandrie: questions de method", dans : Alexandrie médiévale 1 , IFAO, Etudes alexandrines 3, Le Caire.

- Gonzales, A. (1977), Voyage en Egypte de 1665-1666, traduit par Charles Libois S.J., $19^{\text {ème }}$ vol., IFAO, Le Caire.

- Grossmann, P. (1991), Abu Mina, CoptEnc 1, Macmillian publishing company, New York.

- Jean de Nikiou (n.d), Chronique de Jean, Zotenberg.

- Livingstone, L.A. (1997), The Oxford Dictionary of the Christian church, 3rd edition, edited by F.L. Cross, Vol. I, Oxford University press.

- Lubenau, R. (1972), Voyages en Egypte pendant lea années 1587-1588, $6^{\text {ème }}$ Vol., IFAO, Le Caire.

- Mackean, D.D. (1920), Christian Monastiscim in Egypt, society for promoting christian knowledge, Macmillian publishing company, New York.

- Magdy, M. (2014), " Les Anciennes églises d'Alexandrie à travers les siécles", publications of the Archeological Society of Alexandria, Archeological\& Historical studies, No 15, Alexandria, pp.201-250.

- Martin, A. (1989), Topographie et liturgie: le problème des "Paroisses" d'Alexandrie, Actes du XIème Congrès International d'Archéologie chrétienne, (21-28 septembre 1986), Ecole française de Rome.

- Martin, M.( 2015), Monastères et Sites Monastiques d'Egypte. BEC 23, IFAO, Le Caire.

- Meinardus, O.F.A. (1965), Christian Egypt Ancient and Modern. $2^{\text {nd }}$ ed., AUC Press, Cairo.

-Meinardus, O.F.A. (2000), Two thousand years of Coptic Christianity, AUC Press, Cairo.

- Molinghen, A.L. (1968), " La Mort d'Arius", Byzantion, Vol.38, No.1, pp.105-111.

- Moorsel, P. (1995), Les peintures du monastère de Saint Antoine près de la mer rouge, MIFAO CXII, Le Caire.

- Morisson, A. (1976), Voyage en Egypte de 1697, $17^{\text {ème }}$ vol., IFAO, Le Caire.

- Neitzschitz, G.Chr. (1974), Voyage en Egypte de 1636, $13^{\text {ème }}$ Vol., IFAO, Le Caire.

- Palerne, J. (1971), Voyage en Egypte

1581, par Serge Saumeron, vol. 2, IFAO, Le Caire.

- Perkins, J.B.W. (1949), "The Shrine of St. Menas in the Maryut", Papers of the British school of Rome, Vol.17, pp.26-71.

- Roncaglia, M.P. (1991), Arius, CoptEnc 1, Macmillian publishing company, New York.
- Sadek, A.et B.(2003), "Petit guide Hagiographique pour la visite de l'église Saint Antoine", le monde copte 33, Paris, pp.27-72.

- Sennoune, O. (2008), Alexandrie et les récits des voyageurs du VIème siècle à 1798, thèse de doctorat en histoire, Université Lumière, Vol. I, La France, Lyon 2.

- Sharaf El-Deen, Rehab .M. ( 2008), Coptic Monuments at Pagan sites in Egypt and utilizing them in the field of Tourism and Hotels, Master thesis unpublished, Faculty of Tourism and Hotels, Alexandria.

- Socrates Scholasticus (1892), Ecclesiastical History (History of the Church), 7 Books, London and New York.

- Tedesschi, S. (1991), Ethiopian Prelates, CoptEnc3, Macmillian publishing company, New York.

- Vansleb, R.D. (1677), Nouvelle Relation en forme de journal d'un voyage fait en Egypte 1672-1673, Paris.

- Vaujany, H.(1885), Alexandrie et la Basse-Egypte, Bibliothéque Nationale de France.

- Viallamont, (1971), Voyage en Egypte des annèes 1589-1591, 13ème Vol., IFAO, Le Caire.

- Viaud, G. (1979), Les Pélerinages Coptes en Egypte d'après les notes du Qommos Jacob Muyser, IFAO, 2ème trimestre, Le Caire.

- VolKoff, Oleg V. (1972), Voyageurs russes en Egypte, Tome 32 , IFAO, Le Caire.

- Wilkinson,G. (1847), Handbook for travellers in Egypt, Harvard college libary, John Murray, London-Paris.

$$
\text { Wipszycka, E.(1988), "La }
$$

Christianisation de l'Egypte aux IVème - Vième siécles aspects sociaux et ethiques", Aegyptus, anno 68, No 1-2 (gennaio- dicembre 1988), pp.117-165.

- Wucher King, J. (1989), Historical Dictionary of Egypt, AUC press, Cairo.

$$
\begin{aligned}
& \text { قائمة المراجع والمصادر العربية: }
\end{aligned}
$$

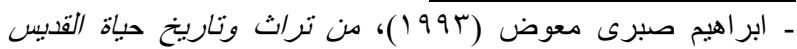

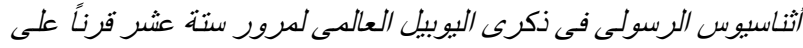

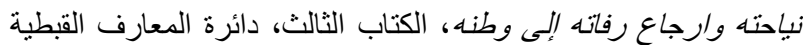

$$
\begin{aligned}
& \text { الأرثوذكسية، مطبعة السلام، القاهرة. }
\end{aligned}
$$

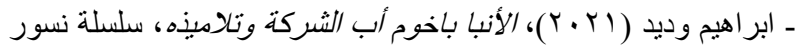

$$
\begin{aligned}
& \text { البرية، تحت الطبع، القاهرة. }
\end{aligned}
$$

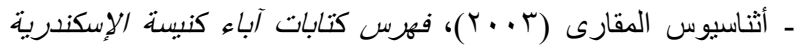

$$
\begin{aligned}
& \text { (الكتابات اليونانية)، دار نوبار للطباعة، القاهرة. }
\end{aligned}
$$

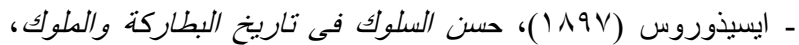

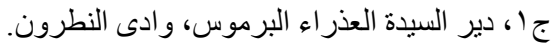

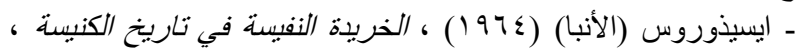

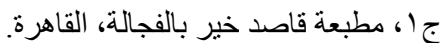

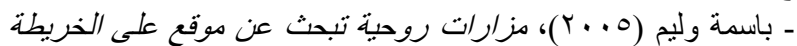

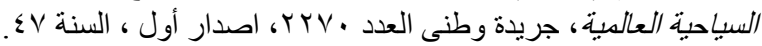


- تادرس يعقوب ملطى (1. (Y)، آباء مدرسة الاسكندرية الأولون، مطبعة الكرنك، الاسكندرية.

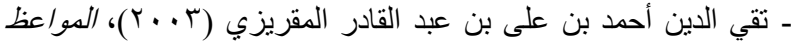

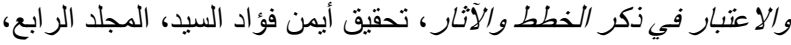

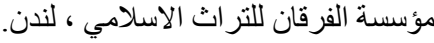

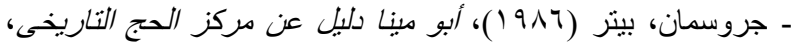

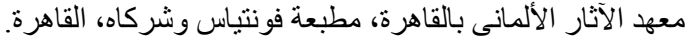

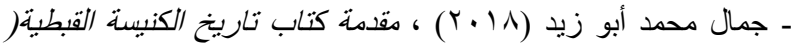

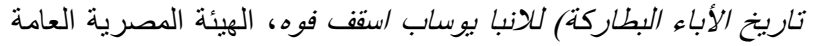

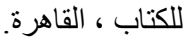

- جودت جبرا، جيرترود.ج.م.فان لوون وكارولين لودفيج (7 ( • (Y)،

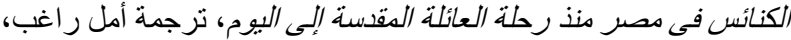
شركة أور اسكوم تليكوم، القاهرة.

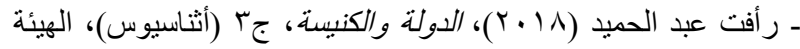
المصرية العامة للكتاب، القاهرة.

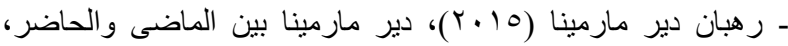
السلام للطباعة، أسبوط.

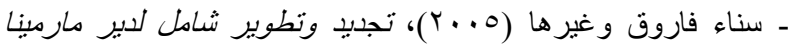

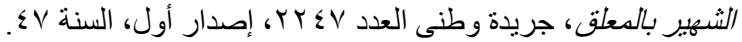

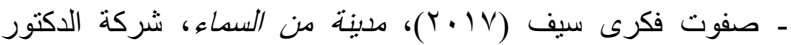

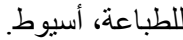
ـ صمؤيل السريانى (د.ت)، الدليل إلى الكنائس والأدبرة القدبية من الجبزة إلى أسوان، مكتبة المحبة ، القاهرة.

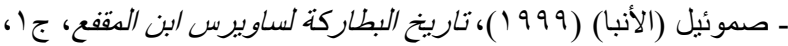
النعام للطباعة و التوريدات ، القاهرة.

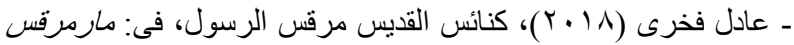

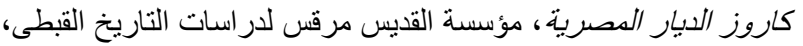

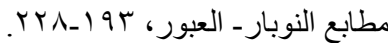

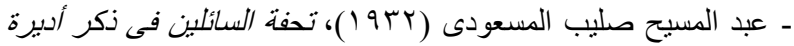

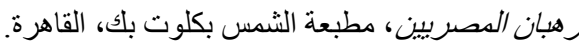

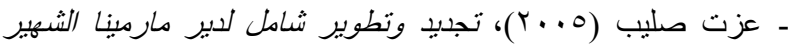

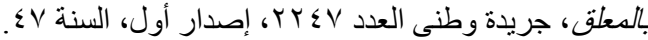

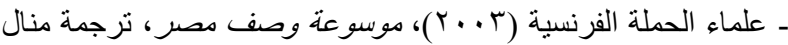
بشير، الهيئة المصرية العامة للكتاب، القاهرة.

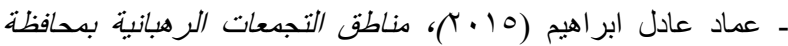

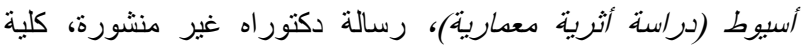
الأداب، جامعة أسيوط.

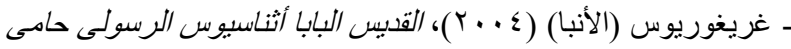

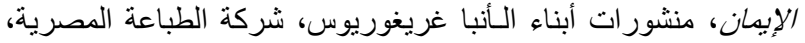

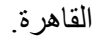

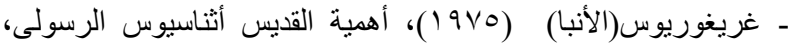

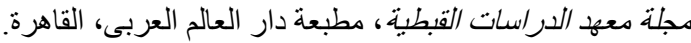

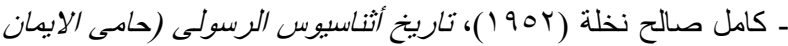
القويم)، مطبعة النيل الحديثة بالفجالة، القاهرة.

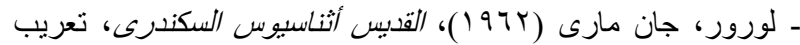

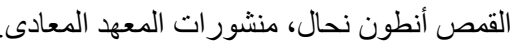

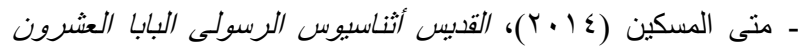

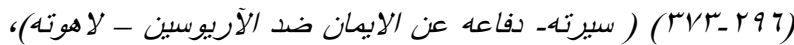

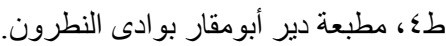

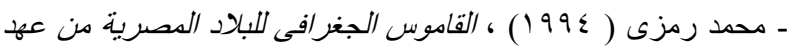

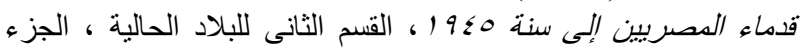

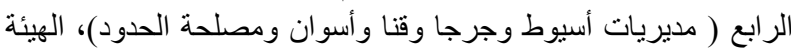
المصرية العامة للكتاب، القاهرة.

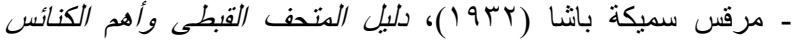

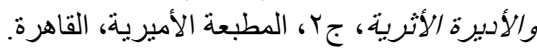

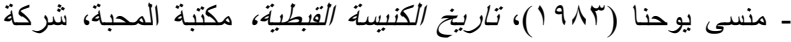
هارمونى للطباعة، القاهرة.

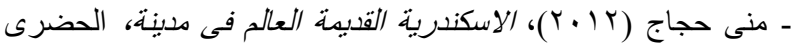
للطباعة، الاسكندرية.

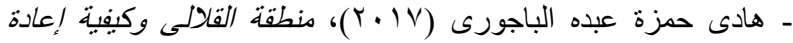

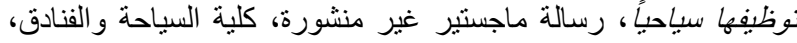
جامعة الاسكندرية.

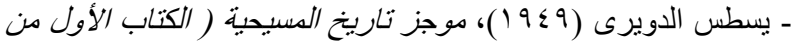
بدء المسيحية إلى عصر المجامع المسكونية)، مطبعة ملجأ الأيتام القبطى الإنى

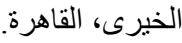

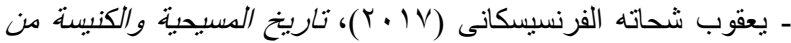

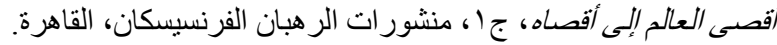

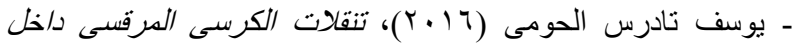

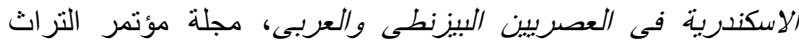

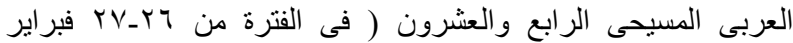

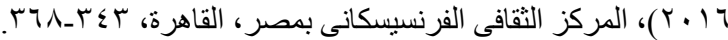




\title{
Monuments in Egypt related to Saint Athanasius
}

\section{Mary Magdy Anwar}

Associate professor in- Tourist Guiding Department

Faculty of Tourism and Hotels Alexandria University

\begin{abstract}
Since the appearance of Christianity in Egypt with the preaching of Saint Mark, several patriarchs have followed one another starting with Saint Mark followed by Saint Anianus, then by seventeen others until the arrival of the twentieth Pope Saint Athanasius the Great who was enthroned on 8 Bashans, in the year 44 of the martyrs - 328 AD. after the death of Pope Alexander.

This pope is considered one of the most revered patriarchs of the See of Saint Mark. He led the church for 46 years and was exiled 5 times from his seat.

Despite the many persecutions he suffered, he remains one of the pillars of the Coptic Orthodox Church. He was the first pope who ordained the first bishop of Ethiopia, as soon as the religious situation was stabilized in that country. He was also the first to look for the mixture of balm for the preparation of the Holy Chrism (oil of Myron) in Alexandria. Likewise, he fought fiercely against the heresy of Arius.

Hence, the monuments which are associated with him, cannot be neglected. So the aims of this research is toshed light on the biography of this saint, the historical events he experienced while highlighting the main monuments he had built in Egypt such as the Saint Athanasius Church in Alexandria and the first monumental church in Abu Mina.

This is in addition to the places where he was exiled and which were effectively related to him such as the El-Zawya monastery located in the governorate of Assiut, the cave of the monastery of Saint Mina the suspended in Assiut and many other monuments of the Upper Egypt. These monuments, which reflect the importance of this remarkable personality, represent an undeniable part of our Coptic heritage.
\end{abstract}

Key words: Athanasius, Churches, Monasteries, Exile, Alexandria. 